\title{
"Bouncing-Back" and Relaxation were the Most Valued Skills Ac- quired by 369 Students During a School-Based Resiliency Program
}

Keywords: Cognitive behavioral therapy; Penn resiliency program (PRP); Screening; Substance misuse; Youth mental health

\section{Abstract}

Background: Drug and alcohol use during adolescence continues to be concerning, and evidence suggests this can be reduced with resiliency training. Here we provide results from a qualitative inquiry into the possible effectiveness of a resiliency program given to students in Grades 6-8 (aged 11-14) who were taking part in a larger program.

Methods: As part of a larger series of interventions in schools (EMPATHY program), a translated resiliency program for youth, called Op Volle Kracht (OVK) in its original Dutch this in turn is a modified version of the Penn Resiliency Program (PRP). It was delivered during classroom time to 2,063 students in Grades 6-8 (aged 11-14). Qualitative data on student perspective on OVK was collected on an anonymous basis via electronic tablets. Of this population of 2,063 a total of 369 (18\%) students participated in this qualitative study.

Findings: Through content analysis, four main themes were identified. Students across all Grades reported learning new skills as the most appreciated feature of the OVK, specifically learning how to "bounce-back" from difficult situations. Learning relaxation techniques and tools to relieve stress were also reported as useful. Students in Grade 8 favoured incentives more than their younger peers, while the need for an interactive program was reported to be less useful with the older age group.

Conclusions: This analysis is helpful in providing real-world feedback regarding what students, aged 11-14, found most helpful in dealing with their challenges. Overall, skills-training was the most valued feature, and this can be incorporated in future interventions to increase mental health resiliency in children and youth.

\section{Introduction}

Substance use by adolescents is a continuing concern [1]. Currently, youth between 15 and 24 years exhibit the highest risk of increased rates of substance misuse of any age group [1-3]. Use of drugs or alcohol is increasingly measured in youth and evidence suggests that substance misuse increases the likelihood of adverse consequences to the developing brain, negatively impacting impulse control, motivation, and cognition [4-7]. Substance use in adolescence also increases the risk of mental health problems, such as depression, suicidality, overall morbidity and mortality [8,9]. Alcohol use in Canada occurs in approximately $25 \%$ of youth between 11 and 18 years, and just under $13 \%$ consume 5 or more drinks during a single time period (known as binge drinking) $[10,11]$. There is evidence that these rates increase with age, subsequently elevating

\section{Journal of}

\section{Addiction \& Prevention}

Deena M. Hamza ${ }^{1 *}$, Stu Henry ${ }^{3}$, Andrew J. Greenshaw ${ }^{1}$, Shereen M. Hamza ${ }^{4}$, Rutger C. Engles ${ }^{5}$ and Peter H. Silverstone $e^{1,2}$

'Department of Psychiatry, University of Alberta, Edmonton,

Canada

${ }^{2}$ Strategic Clinical Network for Addiction and Mental Health, Alberta Health Services, Alberta, Canada

${ }^{3}$ Red Deer Public Schools, Red Deer, Alberta, Canada

${ }^{4}$ Department of Pediatrics, University of Alberta, Edmonton,

Canada

${ }^{5}$ Trimbos-Institute, P.O. Box 725, 3500 AS Utrecht, The Netherlands

\section{*Address for Correspondence}

Deena M. Hamza, Department of Psychiatry, University of Alberta, 205 College Plaza, 8114 -112 Street, Edmonton, Alberta, Canada, Tel: +1-780-4920789; E-mail: dh9@ualberta.ca

\section{Submission: 22 June, 2018 \\ Accepted: 23 July, 2018 \\ Published: 30 July, 2018 \\ Copyright: @ 2018 Hamza DM, et al. This is an open access article distributed under the Creative Commons Attribution License, which permits unrestricted use, distribution, and reproduction in any medium, provided the original work is properly cited.}

the risk of morbidity and mortality [10]. In fact, Canadian statistics also show that $86 \%$ of Grade 12 students engage in alcohol use, with $68 \%$ having experienced binge drinking and approximately $50 \%$ have tried an illicit substance [10]. These findings flag adolescent substance use as an area of continuing concern, with a need to develop more accessible and effective appropriate prevention and early intervention strategies. A useful approach to this problem area may be to find ways to increase individual resiliency, as it has been suggested that increasing the resiliency of youth may help minimize subsequent abuse [12-14]. Most resiliency programs have focused upon reducing depressive symptoms and have not measured the impact on drug or alcohol use, or what focussed on aspects of behaviour that may be most important.

The Penn Resiliency Program (PRP) is a cognitive-behavioural prevention program that focuses on reducing symptoms of depression in adolescents between 10 and 14 years [15]. This program is built on positive education, where learning traditional skills for academic purposes is paired with learning skills for happiness and overall wellbeing [16-18]. The PRP consists of 12, 90-minute classroom sessions that introduces students to essential concepts of cognitivebehavioural skills (i.e. how our thoughts lead to our feelings, and subsequently lead to our actions) and problem solving skills [19]. Students learn how to challenge maladaptive thought patterns, identify "mind-traps", and develop skills to "bounce-back" from negative situations [19]. In addition, PRP educates students on social competence skills, such as assertiveness and resistance training (i.e. saying no to substance use; dealing with peer pressure) [19]. Each of the PRP components is introduced to students in groups, followed by discussions, role play, and homework assignments to practice newly developed skills [19]. As with various prevention programs designed 
specifically for adolescents, the PRP has produced mixed results in terms of a reduction in depressive symptoms post-PRP [15,20,21]. Among the reasons for variation in outcomes, significant factors may be related to cultural appropriateness of the content and style of the program, participant characteristics, length of interventions, activities, and administration of the program by trained professionals [22,23].

To address some of these issues a more recent version of the PRP program was developed in the Netherlands where it is called Op Volle Kracht (OVK), translated into English as "At Full Force" $[24,25]$. Similar to the PRP, the OVK focuses on processing thoughts, feelings, and behaviours, and how these cognitive schemas determine an individual's view of the world [24]. This approach bridges three prominent theories - Ellis' ABC Model, and the Cognitive Theories of both Beck AT and Seligman ME [24,26-30]. The OVK program involves 16 classroom sessions lasting 45-50 minutes each, the usual duration of each class $[21,24]$. In addition, OVK explicitly divides the lessons into two groups: lessons 1-8 focuses on educating students on cognitive-behavioural principles, such as how one's actions begin with automatic thoughts (positive or negative) to the situation at hand, and how to challenge maladaptive thoughts. These are followed by lessons 9-16 which focus on applying newly learned cognitivebehavioural skills to deal with common events in adolescent life, including improving problem solving, relaxation, negotiation, and decision making skills $[24,25]$. Follow-up assessments at one year post-OVK suggest positive effects of the program, although it is recognized that most changes take considerable time [25,31]. It remains uncertain if OVK, when it is the only intervention given, leads to long-lasting benefits on mood, and there is no previous data on possible impacts on substance misuse [32].

To date, the literature suggests there is a need for well-studied prevention and intervention programs that can potentially reduce substance misuse in youth. Ideally, these could be administered within school settings as this is likely to impact the largest number of youth. Amidst a variety of proposed interventions, one suggested approach for youth is to utilize a combination of universal screening, brief intervention for those at high risk, and referral to treatment when this requirement is identified, with this comprehensive approach having the acronym SBIRT [33-37]. In principal, SBIRT may be a versatile or flexible strategy that can be used in sites such as primary care or schools, and can be used as first-line treatment for adolescent substance misuse, or as a stepped approach to more intense or specialized treatment $[36,38]$. This comprehensive approach may also have public health benefits since early opportunistic identification and treatment of individuals engaging in risky substance use may delay, and optimally prevent, the onset of substance use problems $[37,39]$. Implementing this program in the most appropriate setting, within schools (or possibly also in primary care), has proved challenging despite the potential attributes of this approach [37,38]. Several key issues arise when considering the most appropriate methods to utilize SBIRT most effectively, including the choice of screening tools, the nature of any brief interventions, and the best methods for subsequent referral to treatment $[4,36,40,41]$.

While there is understanding of the need for early prevention strategies targeting preventing mental health issues, little is known about the opinions and responses of youth who engage in programs designed for them. Thus, in the present publication we describe student feedback on the universal prevention program OVK for symptoms of depression. This component of the program was contained within a larger school-based SBIRT program (EMPATHY), in which we also attempted to examine the effectiveness of SBIRT on youth mental health outcomes, including substance misuse $[31,32,42,43]$.

\section{Methods \\ Study design}

The detailed methodology for subject recruitment, timing, and inclusion, is detailed elsewhere but, in brief, the EMPATHY program was an observational study implemented in Red Deer, a city in Alberta with a population of approximately 100,000 people in collaboration with Red Deer Public School system [31,42]. All schools in the public system took part, so it was a community-wide sample. The primary outcomes of interest were youth suicidality and depression; secondary outcomes of interest were substance misuse, self-esteem, and quality of life. The EMPATHY program followed a comprehensive prevention/intervention approach, and provided universal screening to all students in Grade 6-12 in the Red Deer Public School District at four time points over 15-months [31].

Students who had the most severe symptoms were identified, with those in the most severe $10 \%$ being offered specific additional interventions including participation in an online intervention based on cognitive behavioural therapy approaches. Students who received parental consent and provided assent to participate in the brief online intervention were screened upon completion of the program. Those who continued to have significant symptoms were then referred to treatment to either primary care physicians or specialist services, depending on needs.

In addition, during the period September 2014-June 2015 all students in Grades 6-8 had a total of 16 resiliency lessons (OVK) as part of the irregular school curriculum. This was delivered by a specifically trained staff member (not a teacher), called a Resiliency Coach. Students were also offered the opportunity to provide feedback on their experience with OVK, and this feedback data is the basis for the current analysis.

For qualitative insight into the perspective of the students in Grades 6-8 who experienced the OVK program, we used a mixed methods paradigm to assess changes in CRAFFT substance use scores as well as a qualitative inquiry into social processes surrounding the OVK component of the EMPATHY program [32]. To help understand student perspectives on the positive and negative aspects of the 16 lesson OVK program, including possible interactions between people guiding this process, the most appropriate method was to provide students with a semi-structured approach to share their thoughts. Our study involved an initial open question posed to students in the hopes of understanding potential positive and negative attributes of the OVK program, rather than focusing solely on symptom outcomes.

Data collection began with a sampling strategy where we invited all students in Grades 6-8 who experienced OVK lessons to provide feedback electronically on what they liked about the program. Students in Grades 6-8 were invited to provide feedback on OVK 
Citation: Hamza DM, Henry S, Greenshaw AJ, Hamza SM, Engles RC, et al. "Bouncing-Back" and Relaxation were the Most Valued Skills Acquired by 369 Students During a School-Based Resiliency Program. J Addiction Prevention. 2018;6(1): 7.

lessons anonymously through the use of an electronic tablet. The question posed to students was "What did you like about Resiliency lessons?". Students were then able to describe any positive, and negative, attributes of the OVK lessons. Participation was voluntary. No personal information was collected; however, each response was paired with the student's Grade. We wanted to determine if the lessons were preferred more by one age group, and if the factors of interest differed with increasing age.

\section{Results}

\section{Content analysis}

The analysis strategy focused on both summative content analysis and interpretation in which as many ideas and details were noted and initially coded. These broad ideas began with a brief examination of the first few responses from students from each Grade (Table 1). This analysis progressed toward more focused coding with remaining responses. Constant comparison strategy was used to compare initial data with data, data with concepts, and between concepts until a select set of content was observed to be central to student responses as a whole. Two researchers (DMH and SMH) developed coding systems individually and through team discussions to ensure internal validity of inter-rater procedures. Any discrepancies were discussed until full agreement was reached.

Through broad coding followed by focused coding, we (DMH and $\mathrm{SMH}$ ) were able to identify four prominent categories in which to organize our detailed findings on student perspective on participating in OVK lessons. These four categories are: engaging; skills training; incentives; and overall disinterest. Under each category factors were highlighted that were consistently found in the content of student responses (Table 2).

\section{Grade 6}

A total of 719 Grade 6 students (mean age 11.3 years) participated and of this population 157 (22\%) Grade 6 students provided feedback on the OVK lessons.

For the category of engaging, $44 \%$ of Grade 6 students found the content, specifically the games and activities to practice newly learned skills, to be fun and interactive (Table 3). A larger group of students (59\%) commented on the skills training received during lessons, with learning how to "bounce-back" as the most favoured feature, followed by stress relief and relaxation techniques (Table 3). Only a small percentage of students (6\%) reported incentives as being what they liked most about OVK (Table 3). The most prominent incentive to participate was their ability to interact with the Resiliency Coach (Table 3). A small percentage of students (8\%) indicated disinterest with the program, demonstrated by the findings that when asked about what they liked about the Resiliency lessons, over $1 / 3$ of this group replied with "nothing" (Table 3 ).

\section{Grade 7}

A total of 712 Grade 7 students participated, and of this population, 115 (16\%) Grade 7 students provided feedback on OVK lessons.

In the category of 'engaging', $32 \%$ of Grade 7 students found the content, specifically the games and activities to practice newly learned skills $(60 \%)$ to be their most favoured aspect of the program (Table 4). Over three-quarters of students $(76 \%)$ found the skills training received during lessons to be memorable, specifically learning how to relieve stress (37\%) and "bouncing-back" (22\%) (Table 4). A larger percentage of Grade 7 students (15\%), than Grade 6 students, reported incentives as being what they liked most about OVK, specifically their ability to interact with the Resiliency Coach (56\%), followed by not having the scheduled class, or delayed test-taking (33\%) (Table 4). Some students indicated disinterest with the program (12\%), often responding with "nothing" (29\%), a neutral response (29\%), or finding the lessons boring (28\%) (Table 4).

\section{Grade 8}

A total of 632 Grade 8 students participated, and of this population, 94 (15\%) Grade 8 students provided feedback on OVK lessons.

Only $16 \%$ of students in Grade 8 found the content of lessons engaging, specifically the games and activities (67\%) followed by overall fun experienced through the interactive nature of the program (33\%) (Table 5). Despite this finding, responses indicate skills training to be the most valued by this age-group (94\%), specifically learning how to relieve stress (23\%), identifying and countering "mind-traps (23\%), and learning how to bounce back from difficult situations (36\%) (Table 5). Students in Grade 8 exhibit the largest percentage (16\%) of all Grades that listed incentives as being what they liked most about OVK; however, unlike the previous two Grades, Grade 8 students valued missing other classes or delayed test-taking (47\%) over their ability to interact with the Resiliency Coach (40\%) (Table 5). Interestingly, Grade 8 students, in comparison to the other two Grades, reported the lowest rate (6\%) of disinterest in OVK lessons (Table 5). In this category, students often did not leave a response $(33 \%)$ or indicated the lessons were boring (33\%) (Table 5).

\section{Variation across Grades}

We found that areas of perceived benefit varied with age. Of particular interest was the consistent perceived value and benefit of skills training from the view of students who actually experienced the program (Figure 1). This suggests that concepts taught to students, such as cognitive sequencing of thoughts to feelings, and subsequent behaviours, is well received by youth 11-14 years of age. Further, concepts such as "bouncing-back" from difficult situations and overall resiliency to combat "mind-traps", or cognitive schemas, were consistently found to be memorable factors in the experience. Findings also suggest the engaging nature of the program, specifically in terms of activities and games, decreased in importance as age increased (Figure 1). While the importance of the interactive nature decreased, the weight of skills learned through the program consistently increased with age from 59\% in Grade 6, 76\% in Grade 7, and $94 \%$ in Grade 8 (Figure 1).

Another interesting finding was the more than two-fold increased importance of incentives associated with the OVK program from Grade 6 to Grade 8 (Figure 1).

\section{Discussion}




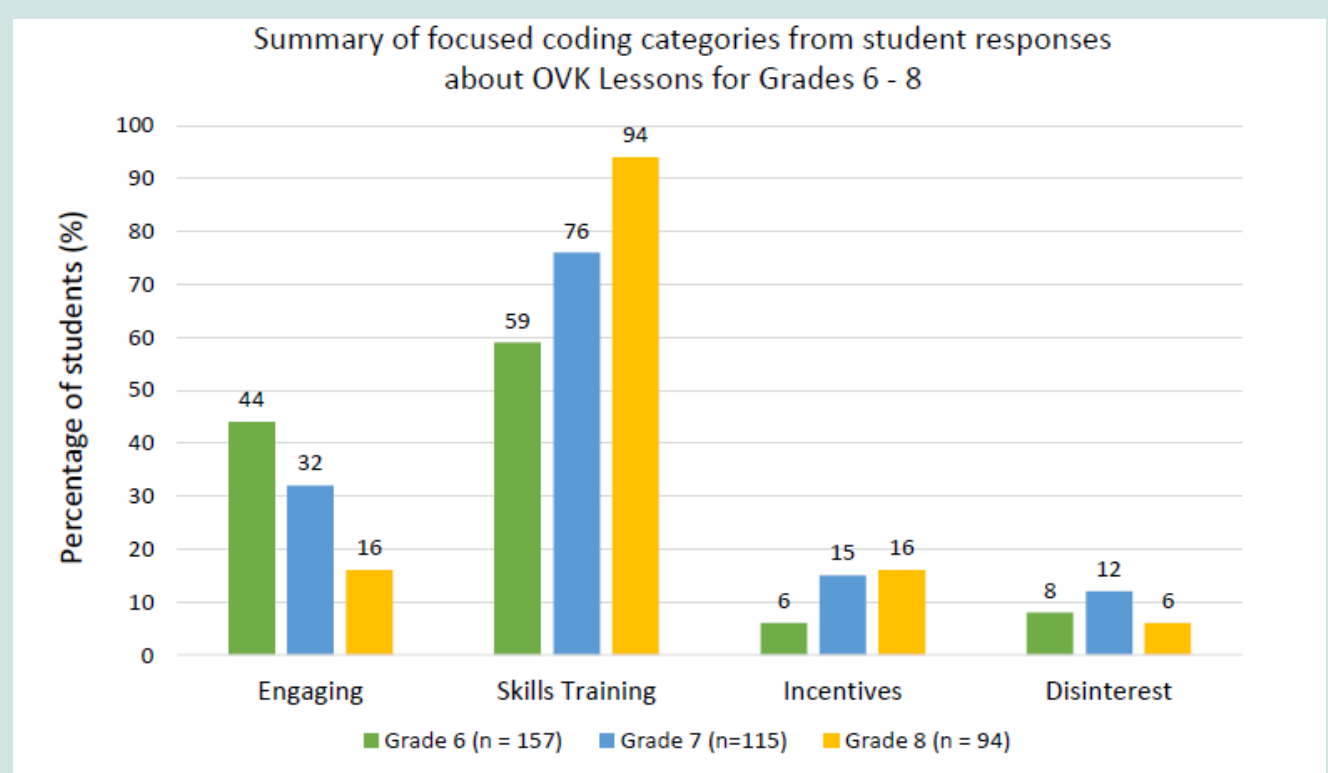

Figure 1: Summary of focused coding categories from student responses about OVK lessons for Grades 6-8.

Figure 1 shows the percentage of students in Grades 6-8 who reported valued aspects of OVK Resiliency lessons upon completion of the program. Skill training was reported as the most valued aspect of Resiliency lessons, increasing with Grade.

The present qualitative inquiry into aspects of OVK Resiliency lessons gives insight into the relative importance placed by students on information presented to them. Certain concept such as cognitive sequencing of thoughts to feeling, and subsequent behaviours, is well received by youth 11-14 years of age. The activities and learnings that were most useful to those students who reported were concepts such as "bouncing-back" from difficult situations, and techniques to address "mind-traps" or distorted cognitive schemas. It was also interesting to see how changes occurred between different age groups, with the utility of activities and games decreasing in importance as age increased (Figure 1). Interestingly, the weight of skills learned through the program consistently increased with age.

There is some evidence that reward development peaks during adolescence, especially in terms of incentive-based motivation, and this may explain why a higher percentage of students in Grade 8 (mean age 13.3) reported incentives as a significant component of OVK lessons versus their younger peers (Figure 1) [44,45]. However, the importance differed from Grades 6 and 7 to Grade 8 from the ability to interact with the Resiliency Coach, to missing scheduled class or delayed test-taking, respectively (Tables 3-5). Our findings also indicate that students in Grade 7 reported more disinterest in the program compared with younger and older peers (Figure 1). The difference in interest level in the OVK program may be an area in need of further research.

\section{Study Limitations}

Only $18 \%$ of the students who took OVK gave feedback, so one limitation is that we are not able to determine if the responders are representative of the larger population. Nonetheless, feedback from a total of 369 students does give some insights into the thoughts of the responders.

In terms of the findings, although some students across all three Grades found the content to be boring, had a neutral response, or didn't respond at all, the reason for their views remains unknown. Further qualitative inquiry through other methods, such as focus groups or interviews would have been beneficial to identify areas for improvement. Additionally, the question posed to students may have been leading, encouraging the student to answer with positive views. Future research into this area may benefit from a more neutral statement, such as "What are your thoughts on Resiliency lessons?". This neutral approach may prompt students to respond with more content in their perspective, positive or negative. We would suggest inclusion of this approach in any future research. It should be noted that our initial goal had been to progress towards in-depth interviews, but unfortunately funding for the EMPATHY program was terminated unexpectedly in June 2015, before we were able to move into this phase of our qualitative inquiry. Had funding continued, we had planned to invite students who had high risk scores for substance misuse, depression, and/or anxiety to provide feedback on their experiences with OVK lessons. We also had another planned phase of inquiry included interviewing students who had experienced only a subset of these lessons in a previous year to see if their perspective differed from those who engaged in the full program. We recognize that our inability to complete the data collection as initially planned is a limitation.

\section{Conclusion}

The Dutch version of the PRP, OVK is a relatively new approach initially implemented initially in a population of youth from lowincome home $[24,25]$. The present study includes the application of an English translation of the OVK program in a population of students between 11 and 14 years. This was part of a larger multi-modal approach primarily designed to decrease psychiatric symptomatology (EMPATHY program). Here we presented information from a qualitative inquiry into responses from students in Grades 6-8 who experienced 16 lessons of OVK. Responses from over 369 students illustrate the importance of resiliency skills training to this age group, 
Citation: Hamza DM, Henry S, Greenshaw AJ, Hamza SM, Engles RC, et al. "Bouncing-Back" and Relaxation were the Most Valued Skills Acquired by 369 Students During a School-Based Resiliency Program. J Addiction Prevention. 2018;6(1): 7.

ISSN: $2330-2178$

Table 1: Sample responses from students in Grades 6 -8 who experienced OVK lessons and initial coding process.

\begin{tabular}{|c|c|}
\hline $\begin{array}{l}\text { Sample response to: "what } \\
\text { did you like about Resiliency } \\
\text { lessons?" }\end{array}$ & Initial broad coding \\
\hline $\begin{array}{l}\text { Grade 6: "I learned different things } \\
\text { so I can stand up for myself when } \\
\text { I get bullied or something like } \\
\text { that. I also liked the brain games } \\
\text { when you are scared of like a test } \\
\text { coming up or a field trip [...]. I also } \\
\text { like the mind-traps [...] and muscle } \\
\text { relaxation" }\end{array}$ & $\begin{array}{l}\text { - Learning new things } \\
\text { - Confidence/self-efficacy } \\
\text { - Self-awareness } \\
\text { - Interactive games/activities } \\
\text { - Resiliency to challenges } \\
\text { - Thinking through problems } \\
\text { - Stress/relaxation skills }\end{array}$ \\
\hline $\begin{array}{l}\text { Grade } 7 \text { : "I like how we talked about } \\
\text { a bunch of different situations to } \\
\text { use resiliency. And we also talked } \\
\text { about }[\ldots] \text { strategies }[\ldots] \text { and how } \\
\text { one negative through decides how } \\
\text { everything after that plays out" }\end{array}$ & $\begin{array}{l}\text { - Discussions } \\
\text { - Applicable situations/Real-life } \\
\text { - Strategies/skills } \\
\text { - Examples } \\
\text { - Resiliency defined } \\
\text { - Thoughts to behaviours } \\
\text { - Self-awareness }\end{array}$ \\
\hline $\begin{array}{l}\text { Grade 8: "How to bounce back from } \\
\text { bad situations and how to change } \\
\text { my mood and thoughts on the spot. } \\
\text { I learned not to get stuck in a fixed } \\
\text { mind set or a mind trap, that events } \\
\text { turn into thoughts that turn into } \\
\text { feeling that turn into actions" }\end{array}$ & $\begin{array}{l}\text { - Bounce-back/resilience } \\
\text { - Dealing with challenges } \\
\text { - Modifying mood/feelings } \\
\text { - Self-awareness } \\
\text { - Mind-traps/cognitive schemas } \\
\text { - Sequence: thoughts, feelings, } \\
\text { - } \text { behaviours } \\
\text { - Skills/strategies }\end{array}$ \\
\hline
\end{tabular}

Table 2: Categories developed from focused coding of student responses about OVK Lessons (Grades 6-8).

\begin{tabular}{|l|l|}
\hline Focused categories & Coding rubric of responses \\
\hline Engaging & - Fun/Interactive \\
& - Activities/Games \\
- Videos & - Stories \\
\hline Skills training & - Self-talk \\
& - Resiliency/ "Bouncing Back" \\
& - Stress Relief/Relaxation \\
& - Mind Traps \\
\hline Incentives & - Candy \\
& - No Class/Test \\
& - Socialization \\
\hline Disinterest & - Resiliency Coach \\
& - Boring \\
& - Mandatory \\
& - Offensive \\
& - Neutral \\
&
\end{tabular}

Table 3: Responses from students in Grades $6(n=157)$ who participated in OVK lessons based on coding rubric.

\begin{tabular}{|c|c|}
\hline Focused categories & Coding rubric of responses \\
\hline Engaging $(n=69,43.9 \%)$ & $\begin{array}{l}\text { - } \text { Fun/Interactive }(30 \%) \\
\text { - Activities/Games }(54 \%) \\
\text { - Videos }(15 \%) \\
\text { - Stories }(1 \%)\end{array}$ \\
\hline Skills training ( $n=93,59.2 \%)$ & $\begin{array}{l}\text { - } \text { Self-talk (9\%) } \\
\text { - Resiliency/ "Bouncing Back" (30\%) } \\
\text { - } \text { Family/Peer Conflict (19\%) } \\
\text { - Stress Relief/Relaxation (25\%) } \\
\text { - } \text { Mind Traps (12\%) } \\
\text { - } \text { Generic "Skills" }(5 \%)\end{array}$ \\
\hline
\end{tabular}

\begin{tabular}{|c|c|}
\hline Focused categories & Coding rubric of responses \\
\hline Incentives ( $n=10,6.4 \%)$ & $\begin{array}{l}\text { - } \text { Candy }(20 \%) \\
\text { - } \text { No Class/Test }(20 \%) \\
\text { - Socialization }(10 \%) \\
\text { - } \text { Resiliency Coach }(50 \%)\end{array}$ \\
\hline Disinterest $(n=13,8.3 \%)$ & $\begin{array}{l}\text { - } \text { Boring }(7 \%) \\
\text { - } \text { "Nothing" }(38 \%) \\
\text { - } \text { Content not applicable }(8 \%) \\
\text { - } \text { Workbooks }(8 \%) \\
\text { - } \text { Mandatory }(8 \%) \\
\text { - } \text { Offensive }(8 \%) \\
\text { - } \text { Neutral }(15 \%) \\
\text { - } \text { Blank }(8 \%)\end{array}$ \\
\hline
\end{tabular}

Table 4: Responses from students in Grades $7(n=118)$ who participated in OVK lessons based on coding rubric.

\begin{tabular}{|c|c|}
\hline Focused categories & Coding rubric of responses \\
\hline Engaging $(n=38,32.2 \%)$ & $\begin{array}{l}\text { - Fun/Interactive }(16 \%) \\
\text { - Activities/Games }(60 \%) \\
\text { - Videos }(19 \%) \\
\text { - Stories }(5 \%)\end{array}$ \\
\hline Skills training $(n=90,76.3 \%)$ & $\begin{array}{l}\text { - Self-talk (7\%) } \\
\text { - } \text { Resiliency/ "Bouncing Back" (22\%) } \\
\text { - Family/Peer Conflict (14\%) } \\
\text { - Stress Relief/Relaxation (37\%) } \\
\text { - Mind Traps (11\%) } \\
\text { - Generic "Skills" }(9 \%)\end{array}$ \\
\hline Incentives $(n=18,15.3 \%)$ & $\begin{array}{l}\text { - } \text { Candy }(11 \%) \\
\text { - } \text { No Class/Test }(33 \%) \\
\text { - Socialization }(0 \%) \\
\text { - } \text { Resiliency Coach }(56 \%)\end{array}$ \\
\hline Disinterest $(n=14,11.9 \%)$ & $\begin{array}{l}\text { - } \text { Boring }(28 \%) \\
\text { - } \text { "Nothing" }(29 \%) \\
\text { - } \text { Content not applicable }(0 \%) \\
\text { - } \text { Workbooks }(0 \%) \\
\text { - Mandatory }(0 \%) \\
\text { - } \text { Offensive }(7 \%) \\
\text { - Neutral }(29 \%) \\
\text { - } \text { Blank }(7 \%)\end{array}$ \\
\hline
\end{tabular}

Table 5: Responses from students in Grades $8(n=94)$ who participated in OVK lessons based on coding rubric.

\begin{tabular}{|c|c|}
\hline Focused categories & Coding rubric of responses \\
\hline Engaging $(n=15,16.0 \%)$ & $\begin{array}{l}\text { - } \text { Fun/Interactive }(33 \%) \\
\text { - Activities/Games }(67 \%) \\
\text { - Videos }(0 \%) \\
\text { - Stories }(0 \%)\end{array}$ \\
\hline Skills training $(n=88,93.6 \%)$ & $\begin{array}{l}\text { - Self-talk (1\%) } \\
\text { - Resiliency/ "Bouncing Back" (36\%) } \\
\text { - } \text { Family/Peer Conflict (7\%) } \\
\text { - Stress Relief/Relaxation (23\%) } \\
\text { - Mind Traps (23\%) } \\
\text { - Generic "Skills" }(10 \%)\end{array}$ \\
\hline Incentives $(n=15,16.0 \%)$ & $\begin{array}{l}\text { - } \text { Candy }(13 \%) \\
\text { - } \text { No Class/Test }(47 \%) \\
\text { - Socialization }(0 \%) \\
\text { - } \text { Resiliency Coach }(40 \%)\end{array}$ \\
\hline Disinterest $(n=6,6.4 \%)$ & $\begin{array}{l}\text { - } \text { Boring }(33 \%) \\
\text { - } \text { "Nothing" }(17 \%) \\
\text { - } \text { Content not applicable }(0 \%) \\
\text { - Workbooks }(0 \%) \\
\text { - } \text { Mandatory }(0 \%) \\
\text { - Offensive }(0 \%) \\
\text { - Neutral }(17 \%) \\
\text { - } \text { Blank }(33 \%)\end{array}$ \\
\hline
\end{tabular}


Citation: Hamza DM, Henry S, Greenshaw AJ, Hamza SM, Engles RC, et al. "Bouncing-Back" and Relaxation were the Most Valued Skills Acquired by 369 Students During a School-Based Resiliency Program. J Addiction Prevention. 2018;6(1): 7.

specifically learning how to "bounce-back" from negative situations, and the benefits of teaching well-validated stress relief and relaxation techniques.

\section{References}

1. CCSA (2014) Abuse. Canadian Drug Trends, Canadian Centre on Substance Use and Addiction, Canada.

2. Patton R, Deluca P, Kaner E, Newbury-Birch D, Phillips T, et al. (2014) Alcohol screening and brief intervention for adolescents: the how, what and where of reducing alcohol consumption and related harm among young people. Alcohol Alcohol 49: 207-212.

3. Leatherdale ST, Hammond D, Ahmed R (2008) Alcohol, marijuana, and tobacco use patterns among youth in Canada. Cancer Causes Control 19: 361-369.

4. Carney T, Myers B (2012) Effectiveness of early interventions for substanceusing adolescents: findings from a systematic review and meta-analysis. Subst Abuse Treat Prev Policy 7: 25.

5. Levy SJ, Williams JF, Committee on substance use and prevention (2016) Substance use screening, brief intervention, and referral to treatment. Pediatrics 138

6. Curtis BL, McLellan AT, Gabellini BN (2014) Translating SBIRT to public school settings: an initial test of feasibility. J Subst Abuse Treat 46: 15-21.

7. Squeglia LM, Jacobus J, Tapert SF (2009) The influence of substance use on adolescent brain development. Clin EEG Neurosci 40: 31-38.

8. Mitchell SG, Schwartz RP, Kirk AS, Dusek K, Oros M, et al. (2016) SBIRT implementation for adolescents in urban federally qualified health centers. $J$ Subst Abuse Treat 60: 81-90

9. Diego MA, Field TM, Sanders CE (2003) Academic performance, popularity, and depression predict adolescent substance use. Adolescence 38: 35-42.

10. Elgar F, Pickett W (2012) Substance use and risky behaviour (Chapter 10). In: Freeman G, King M, Pickett W, et al. (Eds) The health of Canada's young people: a mental health focus, Public health agency of Canada, Canada, pp. 145-164

11. Miller JW, Naimi TS, Brewer RD, Jones SE (2007) Binge drinking and associated health risk behaviors among high school students. Pediatrics 119 : 76-85.

12. Hodder RK, Daly J, Freund M, Bowman J, Hazell T, et al. (2011) A schoolbased resilience intervention to decrease tobacco, alcohol and marijuana use in high school students. BMC Public Health 11: 722.

13. Veselska Z, Geckova AM, Orosova O, Gajdosova B, van Dijk JP (2009) Selfesteem and resilience: the connection with risky behavior among adolescents. Addict Behav 34: 287-291.

14. Mistry R, McCarthy WJ, Yancey AK, Lu Y, Patel M (2009) Resilience and patterns of health risk behaviors in California adolescents. Prev Med 48: 291 297.

15. Brunwasser SM, Gillham JE, Kim ES (2009) A meta-analytic review of the Penn Resiliency Program's effect on depressive symptoms. J Consult Clin Psychol 77: 1042-1054.

16. Gillham JE, Seligman ME (1999) Footsteps on the road to a positive psychology. Behav Res Ther 37 (Suppl 1): S163-S173.

17. Seligman ME, Csikszentmihalyi M (2000) Positive psychology. An introduction. Am Psychol 55: 5-14

18. Seligman ME, Ernst RM, Gillham J, Reivich K, Linkins M (2009) Positive education: Positive psychology and classroom interventions. Oxford Rev Educ 35: 293-311.

19. Gillham JE, Reivich KJ, Seligman ME, Silver T (1990) The Penn Resiliency Program. University of Pennsylvania, Philadelphia, USA.

20. Gillham JE, Reivich KJ, Freres DR, Chaplin TM, Shatté AJ, et al. (2007) School-based prevention of depressive symptoms: a randomized controlled study of the effectiveness and specificity of the Penn Resiliency Program. J Consult Clin Psychol 75: 9-19.

21. Brunwasser SM, Gillham JE (2018) Identifying moderators of response to the penn resiliency program: a synthesis study. Prev Sci 19 (Suppl 1): 38-48.

22. Lopez SJ, Edwards LM, Teramoto Pedrotti J, Ito A, Rasmussen HN (2002) Culture counts: examinations of recent applications of the Penn Resiliency Program or, toward a rubric for examining cultural appropriateness of prevention programming. Prev Treat 5

23. Stice E, Shaw H, Bohon C, Marti CN, Rohde P (2009) A meta-analytic review of depression prevention programs for children and adolescents: factors that predict magnitude of intervention effects. J Consult Clin Psychol 77: 486-503.

24. Kindt KC, van Zundert R, Engels RC (2012) Evaluation of a Dutch schoolbased depression prevention program for youths in highrisk neighborhoods: study protocol of a two-armed randomized controlled trial. BMC Public Health 12: 212 .

25. Kindt KC, Kleinjan M, Janssens JM, Scholte RH (2014) Evaluation of a school-based depression prevention program among adolescents from lowincome areas: a randomized controlled effectiveness trial. Int J Environ Res Public Health 11: 5273-5293.

26. Beck AT (1979) Cognitive therapy of depression. Guilford Press, USA, pp. $1-425$.

27. Beck AT (1967) Depression: clinical, experimental, and theoretical aspects. Harper \& Row Publishers, New York, USA, pp. 1-370.

28. Beck AT (1976) Cognitive theory and emotional disorders. International Universities Press, New York, USA, pp. 1-356

29. Ellis A (1962) Reasons and emotion in psychotherapy. Lyle Stuart, New York, USA, pp. 1-442.

30. Abramson LY, Seligman ME, Teasdale JD (1978) Learned helplessness in humans: critique and reformulation. J Abnorm Psychol 87: 49-74.

31. Silverstone PH, Bercov M, Suen VY, Allen A, Cribben I, et al. (2017) Longterm results from the empowering a multimodal pathway toward healthy youth program, a multimodal school-based approach, show marked reductions in suicidality, depression, and anxiety in 6,227 students in grades 6-12 (aged 11-18). Front Psychiatry 8: 81

32. Hamza DM, Suen VY, Allen A, Cribben I, Goodrick J, et al. (2017) A novel multimodal school-based program, empathy, significantly decreased longterm drug and alcohol abuse as measured by craft scores in 6,227 youth aged 11-18. Child Adolesc Psychiatry Ment Health.

33. Toumbourou JW, Hemphill SA, Tresidder J, Humphreys C, Edwards J, et al., (2007) Mental health promotion and socio-economic disadvantage: lessons from substance abuse, violence and crime prevention and child health. Health Promot J Austr 18: 184-190.

34. Jensen CD, Cushing CC, Aylward BS, Craig JT, Sorell DM, et al. (2011) Effectiveness of motivational interviewing interventions for adolescent substance use behavior change: a meta-analytic review. J Consult Clin Psychol 79: 433-440.

35. Carney T, Myers BJ, Louw J, Okwundu Cl (2016) Brief school-based interventions and behavioural outcomes for substance-using adolescents. Cochrane Database Syst Rev : CD008969.

36. Beaton A, Shubkin CD, Chapman S (2016) Addressing substance misuse in adolescents: a review of the literature on the screening, brief intervention, and referral to treatment model. Curr Opin Pediatr 28: 258-265.

37. Yuma-Guerrero PJ, Lawson KA, Velasquez MM, von Sternberg K, Maxson $\mathrm{T}$, et al. (2012) Screening, brief intervention, and referral for alcohol use in adolescents: a systematic review. Pediatrics 130: 115-122.

38. Sterling S, Valkanoff T, Hinman A, Weisner C (2012) Integrating substance use treatment in adolescent health care. Curr Psychiatry Rep 14: 453-461.

39. Vendetti J, McRee B, Hernandez A, Karuntzos G (2013) Screening, brief intervention, and referral to treatment (SBIRT) implementation models and work flow processes: commonalities and variations. Addict Sci Clin Pract 8 ( Suppl 1): A79. 
Citation: Hamza DM, Henry S, Greenshaw AJ, Hamza SM, Engles RC, et al. "Bouncing-Back" and Relaxation were the Most Valued Skills Acquired by 369 Students During a School-Based Resiliency Program. J Addiction Prevention. 2018;6(1): 7.

ISSN: $2330-2178$

40. Ersche KD, Turton AJ, Chamberlain SR, Müller U, Bullmore ET, et al. (2012) Cognitive dysfunction and anxious-impulsive personality traits are endophenotypes for drug dependence. Am J Psychiatry 169: 926-936.

41. Mitchell SG, Gryczynski J, O'Grady KE, Schwartz RP (2013) SBIRT for adolescent drug and alcohol use: current status and future directions. J Subst Abuse Treat 44: 463-472.

42. Silverstone PH, Bercov M, Suen VY, Allen A, Cribben I, et al. (2015) Initial findings from a novel school-based program, EMPATHY, which may help reduce depression and suicidality in youth. PLoS One 10: e0125527.
43. Silverstone PH, Suen VY, Ashton CK, Hamza DM, Martin EK (2016) Are complex multimodal interventions the best treatments for mental health disorders in children and youth. J Child Adolesc Behav 4: 305

44. Van Leijenhorst L, Gunther Moor B, Op de Macks ZA, Rombouts SA, Westenberg PM, et al. (2010) Adolescent risky decision-making: neurocognitive development of reward and control regions. Neuroimage 51: 345-355.

45. Casey BJ, Jones RM (2010) Neurobiology of the adolescent brain and behavior: implications for substance use disorders. J Am Acad Child Adolesc Psychiatry 49: 1189-1201.

\section{Acknowledgement}

This qualitative inquiry could not have been possible without the support and dedication from the Resiliency Coaches of the EMPATHY Program, along with the students from Red Deer Public School District who provided insight into their experiences. 